\title{
ANALISIS IT GOVERNANCE MENGGUNAKAN FRAMEWORK COBIT 5 DOMAIN DSS, MEA DAN BAI
}

\author{
Nadiza Lediwara $^{1}$, Tini A.P Pasaribu ${ }^{2}$, Maya Anggraini ${ }^{3}$ \\ ${ }^{1}$ Program Studi Teknik Informatika, Fakultas Teknik Militer, Universitas Pertahanan, \\ Komplek IPSC (Indonesia Peace and Security Center) Sentul, Sukahati, Kec. Citereup, Bogor, Jawa Barat 16810 \\ ${ }^{2,3}$ Program Studi Sistem Informasi, Fakultas Teknik, Universitas Bengkulu, \\ Jln. W.R Supratman, Kandang Limun, Bengkulu, 38122
}

\section{${ }^{1}$ nadiza.lediwaradidu.ac.id}

\begin{abstract}
Abstrak: Tata Kelola Teknologi Informasi adalah sebuah proses untuk mengatasi permasalahan, dan pengambilan keputusan serta kerangka kerja yang harus dipertanggung jawabkan. Teknologi Informasi yang baik, mampu meningkatkan efektifitas dan efisiensi dalam aktifitas manusia. Evaluasi tata kelola teknologi informasi sangat diperlukan untuk menentukan keberhasilan IT. Dalam mengatasi permasalahan diperlukan kerangka kerja. Salah satunya yaitu COBIT 5 (Control Objective for Information Related Technology version 5). Kerangka kerja Cobit 5 memiliki domain yang bisa dipilih yaitu domain DSS (Deliver, Service and Support), MEA (Monitor, Evaluate and Asses), dan BAI (Build, Acquire and Implement). Metode penelitain ini memakai beberapa metode yaitu metode literatur, metode model konseptual, dan analisis. Tujuan penelitian ini yaitu untuk meningkatkan program audit, mengatasi permasalahan dan pengambilan keputusan dengan menggunakan COBIT 5 dengan menggunakan domain DSS, MEA, dan BAI. Dari penilitian ini dapat disimpulkan bahwa dalam mengatasi permasalahan dan pengambilan keputusan dapat dilakukan dengan menggunakan kerangka kerja COBIT 5 dengan domain DSS, MEA, dan BAI.
\end{abstract}

Kata kunci: Tata Kelola TI, Framework COBIT, DSS, MEA, BAI

\begin{abstract}
:
Information

Technology

Governance is a process for overcoming problems, and making decisions and frameworks that must be accounted for. Information Technology is good, able to increase the effectiveness and efficiency in human activities. Evaluation of information technology governance is needed to determine the success of IT. In overcoming problems, a framework is needed. One of them is COBIT 5 (Control Objective for Information Related Technology version 5). The Cobit 5 framework has selectable domains, namely the DSS (Deliver, Service and Support), MEA (Monitor, Evaluate and Asses), and BAI (Build, Acquire and Implement) domains. This research method uses several methods, namely literature method, method of conceptual model, and analysis. The purpose of this study is to improve the audit program, overcome problems and decision making by using COBIT 5 by using the DSS, MEA, and BAI domains. From this research it can be concluded that in overcoming problems and decision
\end{abstract}

making can be done using the COBIT 5 framework with domains DSS, MEA, and BAI. Keywords: IT Governance, COBIT Framework, DSS, MEA, BAI

\section{PENDAHULUAN}

Perkembangan teknologi informasi untuk sekarang ini sangat dibutuhkan baik oleh pemerintahan maupun perusahaan. Teknologi informasi dibuat untuk memudahkan dalam menangani permasalahan pengambilan keputusan dan menjadikan penggunaannya semakin efektif. Dalam teknologi informasi tentunya memerlukan kerangka kerja yang mengelolanya. Salah satu kerangka kerja yang bisa digunakan yaitu COBIT 5. Dalam COBIT 5, memiliki beberapa domain yang bisa digunakan untuk mengelola teknologi 
Jurnal Pseudocode, Volume VII Nomor 2, September 2020, ISSN 2355-5920, e-ISSN 2655-1845 www.ejournal.unib.ac.id/index.php/pseudocode

informasi yang ada. COBIT 5 membuat penggabungan antara pemikiran terbaru dari tata kelola perusahaan dan juga manajemen. Teknik dan memberikan prinsip-prinsip yang diberikan secara global [1].

COBIT itu sendiri memiliki lima domain utama yaitu:

1. EDM (Evaluate, Direct, and Monitor) merupakah tahapan dalam evaluasi dan monitoring.
2. APO (Align, Plan, Organize) adalah proses dalam menyelaraskan, merencakanan dan mengatur dalam suatu organisasi.

3. BAI (Build, Acquire and Implement) adalah tahapan dalam proses membangun atau merancang dan mengimplementasikan suatu tata kelola.

4. DSS (Delivery, Service and Support) adalah proses mengirim, melayanidan dukungan.

5. MEA (Monitor, Evaluate and Assess) adalah proses memantau, evaluasi, dan menilai.

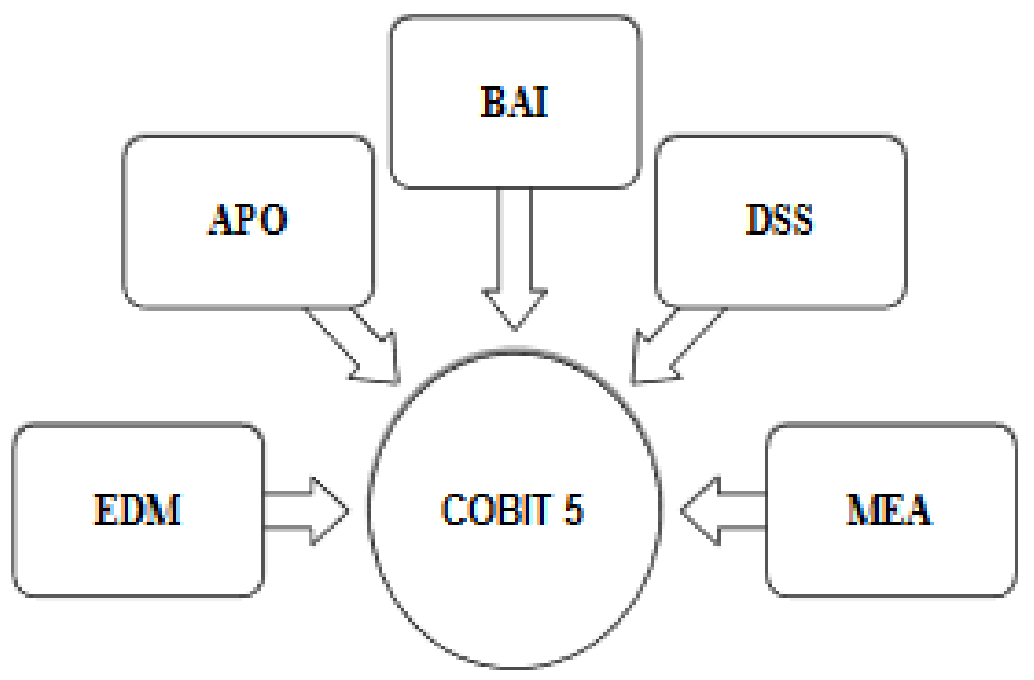

Gambar 1. Domain Cobit 5 [2]

Namun dalam penelitian kali ini yang akan penulis bahas adalah berfokus pada domain DSS, BAI, dan MEA. Domain DSS (Delivery, Service and Support) digunakan untuk menganalisis yang berhubungan dengan pengiriman, layanan dan dukungan. Domain DSS memiliki proses pemetaan yang dilakukan untuk mendapatkan proses domain DSS mana saja yang dapat, masuk dalam kegiatan audit. Dalam penelitian yang membahas Sistem Informasi Manajemen Kota Tanpa Kumuh (SIM KOTAKU), domain DSS dipilih karena lebih fokus untuk menyikapi penyampaian TI pada saat pengiriman dan layanan TI. Lalu domain ini juga dapat mendukung proses bisnis yang ada serta menjamin agar proses bisnis itu tetap terjaga [3].

Domain BAI (Build, Acquire and Implement) bertujuan untuk menetapkan persyaratan, identifikasi, solusi, kelayakan dan kegiatan operasional dalam menjalankan sistem. Domain ini memiliki 10 proses [4].

Domain MEA (Monitor, Evaluate and Assess) ertujuan untuk menanalisis nilai kepatuhan dari peraturan tata kelola. Domain ini memiliki 3 proses [5]. 
Jurnal Pseudocode, Volume VII Nomor 2, September 2020, ISSN 2355-5920, e-ISSN 2655-1845 www.ejournal.unib.ac.id/index.php/pseudocode

\section{METODOLOGI PENELITIAN}

Metode penelitian yang digunakan dalam penelitian ini yaitu antara lain:

- Metode Literatur untuk DSS

Metode Literatur dilakukan dengan mencari jurnal tentang COBIT 5 domain DSS.

- Metode dengan model sonseptual untuk domain $\mathrm{BAI}$

Metode dengan model ini dilakukan dengan cara input, proses dan output. Input yaitu memasukkan data dari reverensi jurnal lain untuk dikelola dalam proses. Proses yaitu menyaring semua informasi dalam masing-masing jurnal, kemudian menyatukannya untuk menghasilkan output. Sedangkat output merupakan hasil dari input yang telah di proses berupa dokumen tata kelola.

- Metode yang digunakan MEA yaitu wawancara, literatur dan observasi. Setelah tahap itu maka akan dilakukan pengumpulan data

- Metode Analisis
Metode yang dilakukan dengan menganalisa referensi agar memperoleh hasil yang baik pada penggunaan framework COBIT 5.

\section{HASIL DAN PEMBAHASAN}

\section{A. COBIT (Control Objective for Information and} Related Technology )

COBIT merupakan suatu praktek manajemen teknologi informasi dan dokumen based practices yang dapat membantu audit manajemen dan menjembatani pemisah atau gap antar permasalahan-permasalahan teknis [6].

B. COBIT 5 (Control Objective for Information and Related Technology Version 5)

COBIT 5 merupakan salah satu dari kerangka kerja yang disejajarkan dengan ISO, CMM dan ITIL. COBIT 5 secara umum memiliki lima prinsip yaitu:

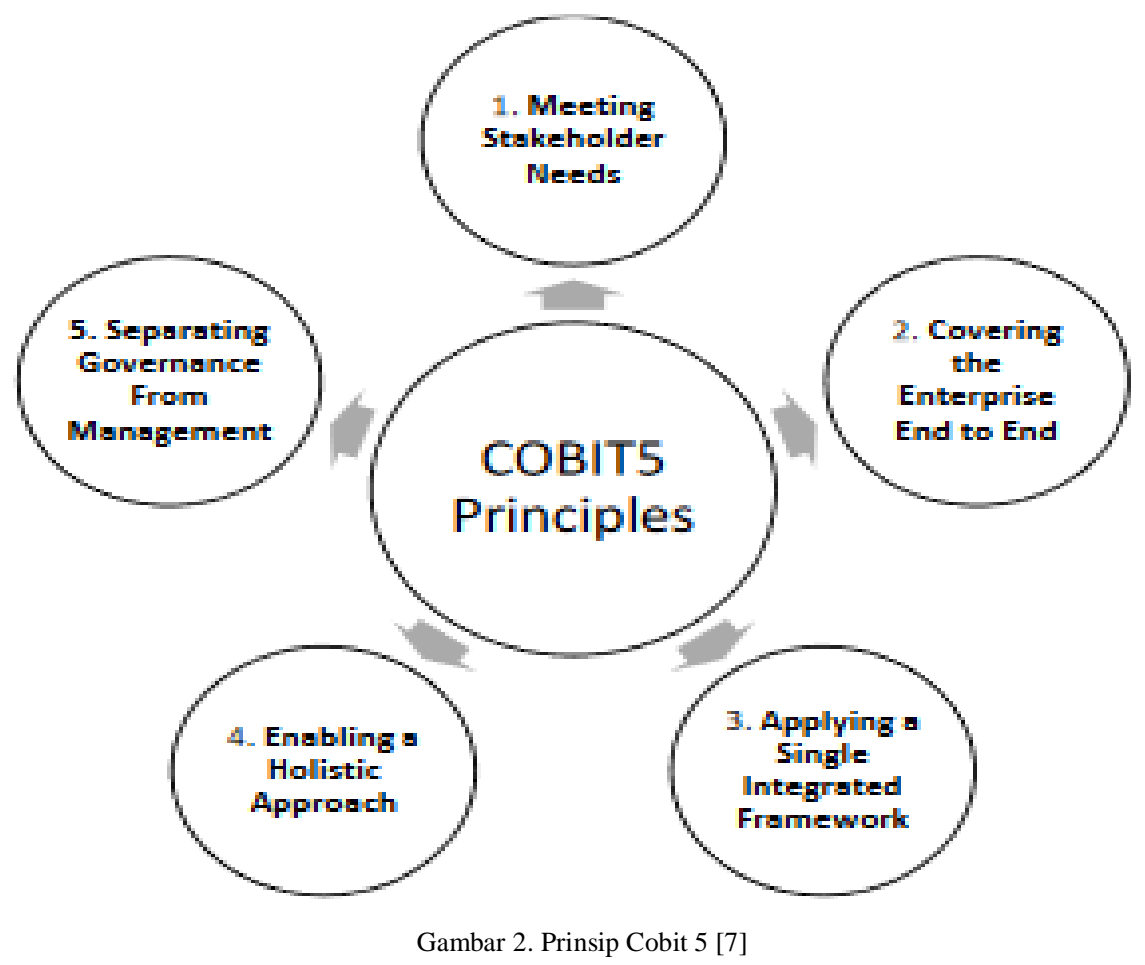


Jurnal Pseudocode, Volume VII Nomor 2, September 2020, ISSN 2355-5920, e-ISSN 2655-1845 www.ejournal.unib.ac.id/index.php/pseudocode

\section{* Pinsip 1: Meeting Stakeholder Needs}

Pemeliharaan keseimbangan antara realisasi keuntungan dan optimalisasi dapat dilakukan dengan memenuhi nilai kehadiran stakeholdernya.
Pada setiap perusahaan memiliki tujuan yang berbeda-beda sesuai dengan konteks perusahaan yang dimiliki oleh perusahaan tersebut.

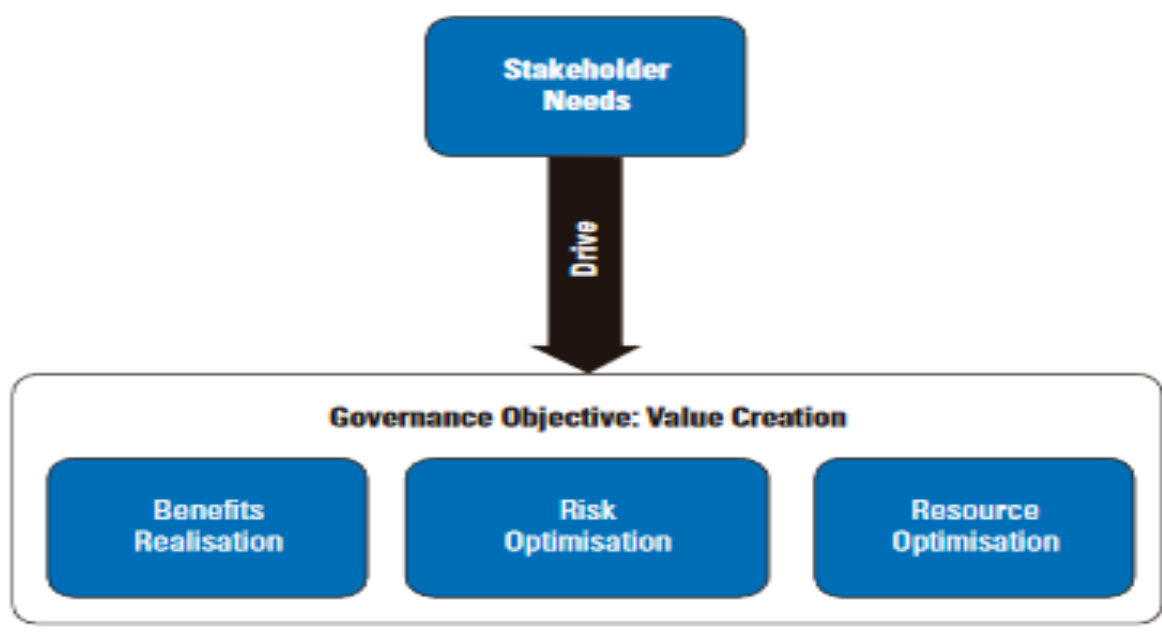

Gambar 3. Meeting Stakeholder Needs [8]

* Prinsip 2: Covering the Enterprise End-to-end

Prinsip 2 ini memiliki 2 cara yaitu, antara lain:

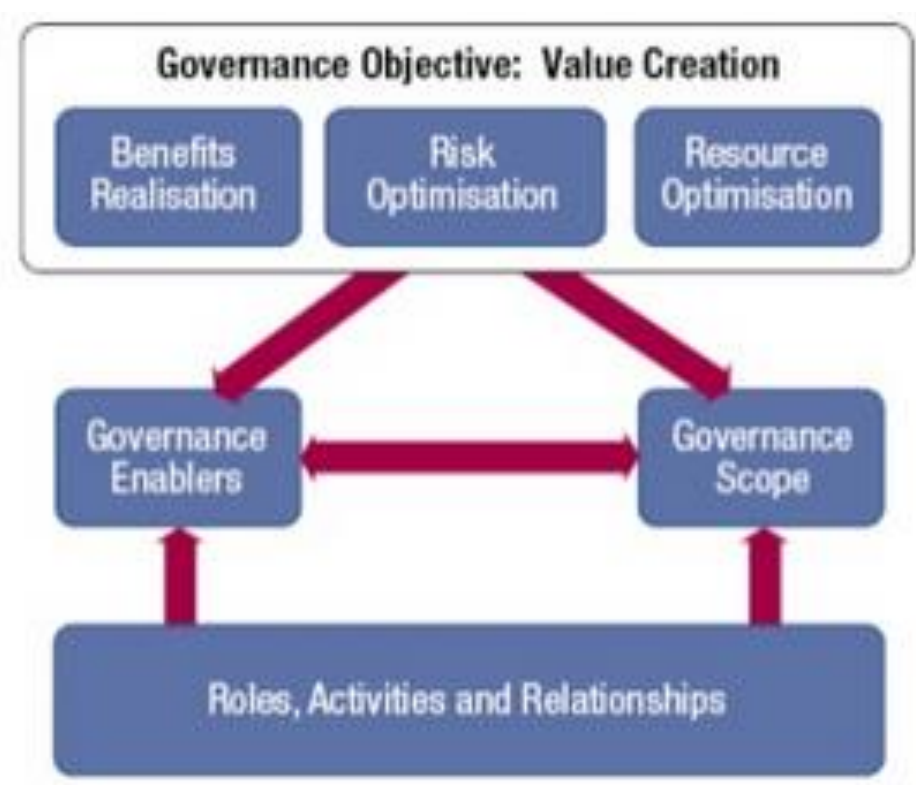

Gambar 4. Covering the Enterprise End-to-end [9]

a. Mengakomodasi fungsi dan proses pada enterprise

b. Mengakomodasi seluruh stakeholder.

* Prinsip 3: Aploying A Single Integrated
Prinsip ini disesuaikan dengan standar framework lain sebagai lingkup manajemen untuk IT Enterprise

Framework 
Jurnal Pseudocode, Volume VII Nomor 2, September 2020, ISSN 2355-5920, e-ISSN 2655-1845 www.ejournal.unib.ac.id/index.php/pseudocode

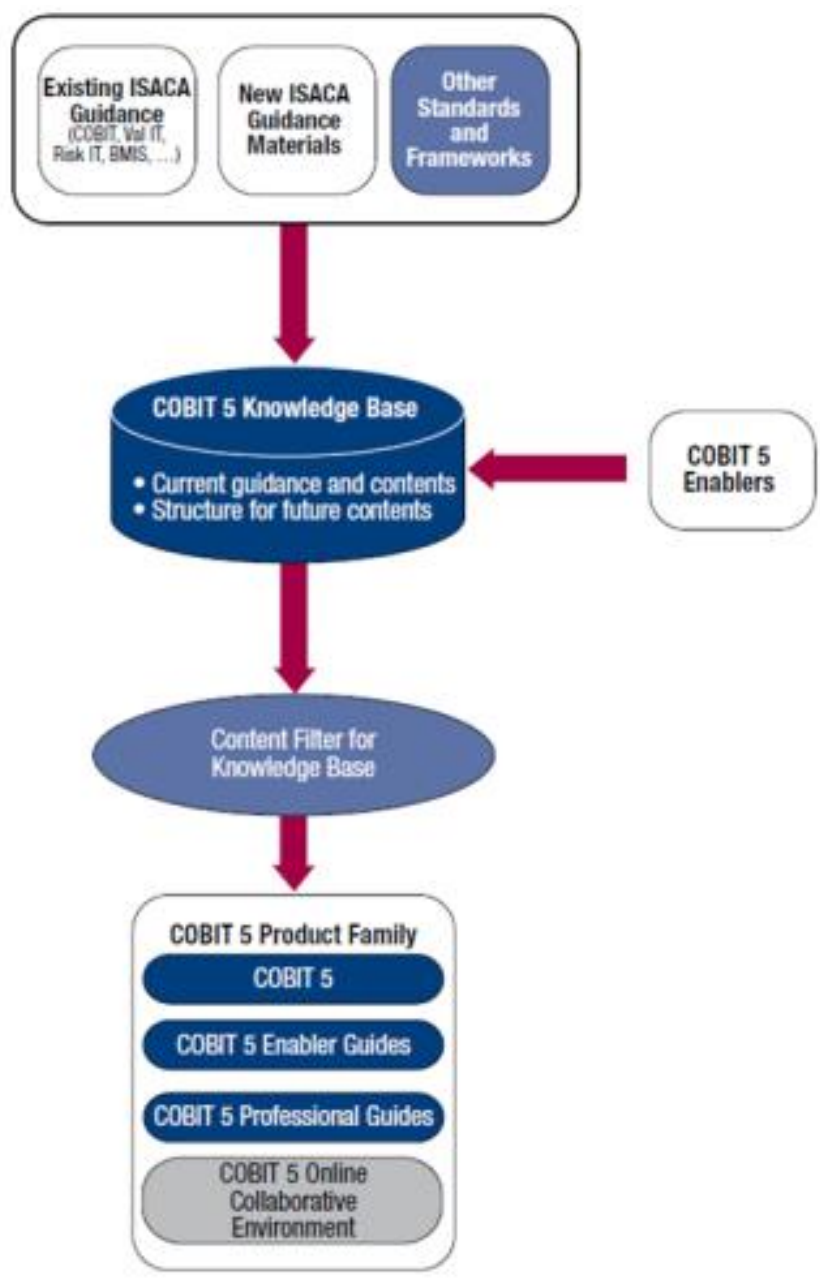

Gambar 5. Aploying A Single Integrated Framework [9]

\section{* Prinsip 4: Enabling a Holistick Approach}

Prinsip ini melakukan pendekatan secara holistic agar pemerintah dan manajemen perusahaan IT melakukan pendekatan yang efektif dan efisien. COBIT 5 sendiri memiliki 7 Kategori enablers yaitu :

a. principle, policies and frameworks

b. processes

c. organisational structures

d. culture, ethics and behaviour

e. informations

f. $\quad$ services infrastructure and applications

g. peoples skills and competencies

\section{* Separating Governance From Manajemen}

COBIT 5 sendiri membedakan tata kelola dan manajemen. Keduanya memiliki tipe aktivitas yang berbeda. Tata kelola yang bertanggung jawab untuk tata kelolanya yaitu Dewan Direksi sedangkan manajemen pertanggung jawabannya adalah Manajemen Eksekutif. 
Jurnal Pseudocode, Volume VII Nomor 2, September 2020, ISSN 2355-5920, e-ISSN 2655-1845 www.ejournal.unib.ac.id/index.php/pseudocode

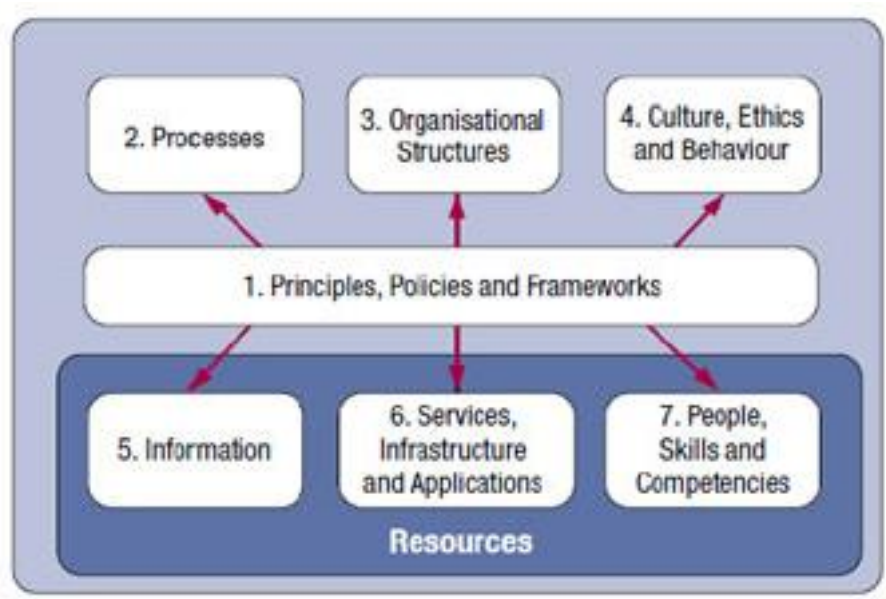

Gambar 6. Enabling a Holistick Approach [9]

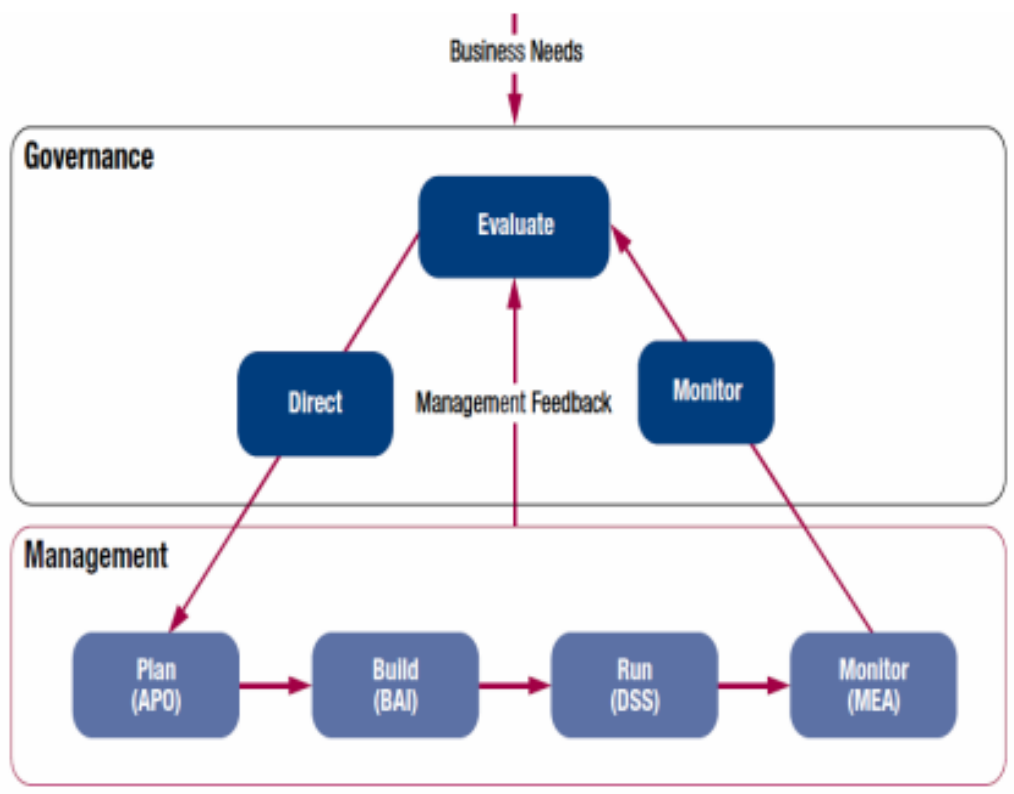

Gambar 7. Ruang Lingkup Governance dan Management [10]

COBIT 5 ini sendiri telah dipakai dalam beberapa penelitan di seluruh dunia. Dikarenakan ada beberapa kelebihan yang didapatkan dari COBIT 5 itu sendiri. Diantaranya:

1. Berhubungan dengan informasi yang relevan dan berkenaan dengan proses bisnis, dan sebaik mungkin informasi dikirim tepat waktu, benar, konsisten, dan berguna [11].

2. Banyaknya sumber daya, tools, serta petunjuk untuk digunakan [12].

3. Proteksi terhadap informasi yang sensitif dari akses yang tidak bertanggung jawab [11].
4. Mencapai keunggulan operasionalmelalui penerapan teknologi yanghandal dan efisien [1].

5. Berhubungan dengan tersedianya informasi ketika dibutuhkan oleh proses bisnis sekarang dan masa depan [11].

\section{Framework COBIT 5:}

\section{Domain DSS}

Domain DSS (Delivery, Service and Support) adalah COBIT 5 yang menganalisa kasus Sistem Informasi yang berhubungan pengiriman, layanan dan dukungan. Domain DSS memiliki proses 
Jurnal Pseudocode, Volume VII Nomor 2, September 2020, ISSN 2355-5920, e-ISSN 2655-1845 www.ejournal.unib.ac.id/index.php/pseudocode

pemetaan yang dilakukan untuk mendapatkan mengelola operasi, mengelola layanan permintaan proses domain DSS mana saja yang dapat, masuk dan insiden, mengelola permasalahan, mengelola dalam kegiatan audit. Domain DSS sendiri layanan yang berkelanjutan, layanan keamanan memiliki 6 proses yang terbagi menjadi DSS01 dan yang terakhir yaitu proses kendali bisnis. sampai DSS06. Proses tersebut antara lain:

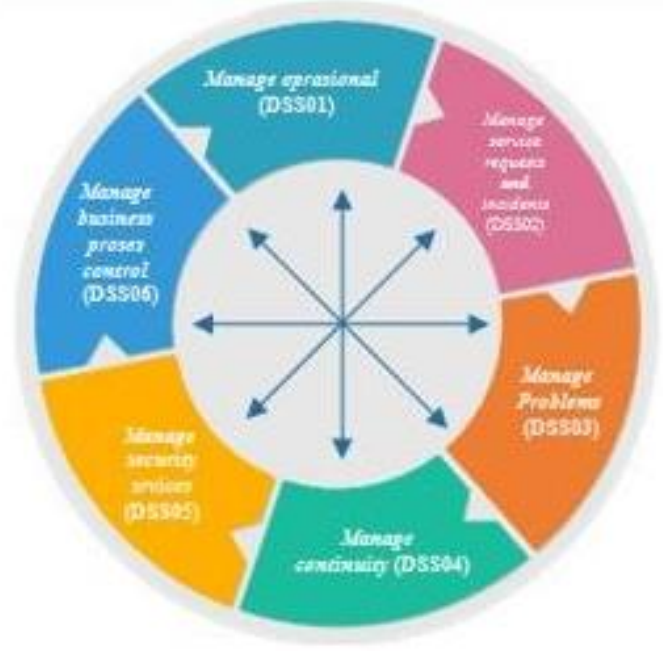

Gambar 8. Domain DSS Cobit 5 [13]

Pada domain DSS memiliki beberapa kategori system availability management, problem management, service desk and incident management, security administration, IT operation and database administration.

\section{Domain BAI}

Domain BAI (Build, Acquire and Implement) digunakan untuk membangun, memperoleh, melaksanakan solusi IT yang dikembangkan dan diterapkan dalam bisnis peusahaan. Domain BAI terdiri dari 10 proses yang terbagi menjadi BAI01 hingga BAI10. Proses tersebut diantaranya mengelola: program dan proyek, defenisi kebutuhan, solusi otomatis, ketersediaan dan kapasitas, perubahan pemberdayaan organisasi, perubahan, penerimaan perubahan dan transisi, pengetahuan, aset dan konfigurasi.

BAI memiliki proses pemetaan yang berfokus pada proses BAI01, BAI02, BAI03 dan BAI08. Walaupun proses pemetaan ini belum berjalan dengan baik pada beberapa perusahaan, namun karena proses ini menjadi kebutuhan maka proes ini tetap dilakukan.

\section{Domain MEA}

Domain MEA (Monitor, Evaluate and Acces) digunakan untuk mengawasi, mengevaluasi dan menilai kebutuhan setiap perusahaan pada proses IT serta kepatuhan dari peraturan tata kelola. Selain itu, penilaian juga dilakukan pada kemampuan proses kontol perusahaan dan pemenuhan proses bisnis. Domain MEA memiliki 3 proses yang tebagi menjadi MEA01 sampai MEA03 yaitu untuk memantau, mengevaluasi dan menilai kinerja dan kesesuaian, system pengendalian serta kepatuhan dan kebutuhan eksternal.

\section{Kesimpulan}

Berdasarkan pengamatan terhadap beberapa sumber yang telah dilakukan maka dapat disimpulkan bahwa setiap domain dalam COBIT 5 memiliki peran masing-masing dalam kerangka kerja dan tata kelola teknologi informasi. 
Jurnal Pseudocode, Volume VII Nomor 2, September 2020, ISSN 2355-5920, e-ISSN 2655-1845 www.ejournal.unib.ac.id/index.php/pseudocode

Framework COBIT 5 merupakan metode yang cukup baik untuk digunakan oleh perusahaan untuk menganalisa tata kelola TI. Harapannya dengan framework COBIT 5 dapat menghasilkan sebuah hasil yang maksimal dalam analisi metode Domain DSS, MEA dan BAI.

\section{REFERENSI}

[1] T. Oktarina, "Tata Kelola Teknologi Informasi dengan Cobit 5," J. Informanika, vol. 3, no. 2, pp. 30-38, 2017.

[2] R. Umar, I. Riadi, and E. Handoyo, "Analisis Keamanan Sistem Informasi Berdasarkan Framework COBIT 5 Menggunakan Capability Maturity Model Integration (CMMI)," J. Sist. Inf. Bisnis, vol. 1, pp. 47-54, 2019, doi: 10.21456/vol9iss1pp47-54.

[3] R. P. Kusuma, “Audit Teknologi Informasi Menggunakan Framework COBIT 5 pada Domain DSS (Deliver, Service, and Support) (Studi Kasus: Konsultan Manajemen Pusat)," J. Digit, vol. 9, no. 1, pp. 97-109, 2019.

[4] Maskur, N. Odolong, and R. Mokodongan, "Implementasi Tata Kelola Teknologi Informasi Menggunakan Framework COBIT 5 di BPMPTSP Bone Bolango," $J$. Masy. Telemat. dan Inf., vol. 8, no. 2, pp. 109-126, 2017.

[5] Suhardi and Z. F. Ikatrinasari, "Evaluasi Kapabilitas Sistem Informasi Manajemen Akuntansi Barang Milik Negara di Satuan Kerja TNI Angkatan Laut,” PERFORMA Media Ilm. Tek. Ind., vol. 15, no. 1, 2016, doi: 10.20961/performa.15.1.13756.
[6] H. Surbakti, "Managing Control Object for IT (COBIT) sebagai Standar Framework pada Proses Pengelolaan ITGovernance dan Audit Sistem Informasi," Respati, vol. 7, no. 19, Jun. 2017, doi: 10.35842/JTIR.V7I19.21.

[7] V. H. A. Nguyen, M. Kolp, Y. Wautelet, and S. Heng, "Mapping IT Governance to Software Development Process: From COBIT 5 to GI-Tropos," in 20th International Conference on Enterprise Information Systems (ICEIS 2018), 2019, pp. 665-672, doi: 10.5220/0006703706650672.

[8] P. Bernard, COBIT 5 A Management Guide. Van Haren Publishing, Zaltbommel, www.vanharen.net, 2016.

[9] ISACA, COBIT 5. ISACA, 2012.

[10] J. F. Andry, "Performance Measurement of IT Governance: A Case Study,” J. Sist. Inf., vol. 12, no. 2, pp. 57-64, 2016.

[11]I. Elyana, “Analisis Pengukuran Kualitas Layanan Sistem Informasi Perbankan dengan Menggunakan COBIT 5,” J. Sains Komput. Inform., vol. 1, no. 2, pp. 237-242, 2017.

[12]M. P. Ismail and W. W. Winarno, "Manajemen Sumber Daya Teknologi Informasi Laboratorium Komputer Menggunakan Balanced Scorecard (BSC) dan COBIT 5," J. Infotel, vol. 9, no. 2, pp. 158-165, 2017, doi: ttps://doi.org/10.20895/infotel.v9i2.169.

[13]I. Riadi and S. Sunardi, "Security Analysis of Grr Rapid Network using COBIT 5 Framework," Lontar Komput., vol. 10, no. 1, pp. 29-39, 2019, doi: 10.24843/LKJITI.2019.v10.i01.p04. 